\title{
CORRESPONDENCE
}

\section{Marine stewardship: a force for good}

Our experience of working with fisheries to prepare them for assessment by the Marine Stewardship Council (MSC) does not square with the view of Jennifer Jacquet and colleagues that the environment does not benefit (Nature 467, 28-29; 2010).

Despite extensive legislation in Europe, fishermen still need an incentive to move towards sustainable exploitation. MSC certification can provide this through access to premium markets for their seafood products (M. J. Kaiser and G. Edwards-Jones Conserv. Biol. 20, 392-398; 2006).

The MSC assessment process has resulted in environmental benefits for various fisheries. For example, the queen-scallop fleet in the Isle of Man, UK, has been fitted with vesselmonitoring systems that will provide accurate electronic data on the scallop fishery's environmental footprint. During the assessment in 2010, half of the territorial sea was closed to scallop dredging and designated a scallopconservation zone, and three protected marine areas were created where towed fishing gear is banned. For the current assessment of the Clyde langoustine fishery in Scotland, fishermen have committed to adopting fishing gear with better selectivity. In addition to improved monitoring systems and data collection, a voluntary catch limitation will be introduced in 2011.

Extensive science programmes are under way in both fisheries to provide data on their wider ecosystem effects, and existing sea-bed maps are being used to avoid the interaction of fishing gear with sensitive habitats.

The Dutch Ekofish plaice fishery, which was MSC certified in 2009, has also committed to sea-bed maps, protected areas and monitoring systems. Fishermen there have publicly supported a research area on Dogger Bank in the North Sea, and plaice-fishing gear with better selectivity is under development.

We believe that the MSC process has refocused the behaviour and attitudes of fishermen in these areas, and has delivered conservation benefits more effectively than formal non-participatory legislation would have.

Michel J. Kaiser Bangor

University, UK, michel.kaiser@bangor.ac.uk Louize Hill WWF Scotland, UK Competing financial interests declared: see http://dx.doi.org/ 10.1038/467531a

\section{Marine stewardship: fair and impartial}

The rigour and integrity of the Marine Stewardship Council (MSC) certification process is much greater than Jennifer Jacquet and colleagues suggest (Nature 467, 28-29; 2010).

The certification process uses independent assessors who have no connection with the MSC, fishing organizations, environmental non-governmental campaigns or other groups. Independent oversight (by Accreditation Services International) ensures impartiality, as does the integrity of the independent scientists and fishery managers who participate in MSC assessments, and the openness of the assessment process. During assessment, stakeholder inputs are actively sought and evaluated, reports are peer-reviewed and open to stakeholder comment, and there is an independent objection process.
Jacquet et al. criticize the certification of some fisheries by Moody Marine (namely Antarctic toothfish and krill) and commend its certification of others (Alaska salmon and Vietnam clam), but all were certified to the same standard using the same process. Any wild-capture fishery may apply for MSC assessment and be evaluated without prejudice.

The MSC standard already requires that certified fisheries include no harmful subsidies and make appropriate use of various conservation measures (not limited to marine protection areas) to limit effects on by-catch, protected species, habitats and overall ecosystem function.

Andrew Hough, Paul Knapman Moody Marine, UK, a.hough@moodyint.com Competing financial interests declared: see http://dx.doi.org/ 10.1038/467531b

\section{Marine stewardship: high bar for seafood}

We disagree with Jennifer Jacquet and colleagues' criticism that the standard of sustainable seafood certification by the Marine Stewardship Council (MSC) is not sufficiently stringent (Nature 467, 28-29; 2010).

They cite Alaska pollock and Pacific hake as species for which certification has been too generous, given their substantial population declines. But any fish population will fluctuate, including sustainably managed fisheries such as these. The allowable catch can simply be reduced when abundance declines. This strategy enabled successful rebuilding of the New Zealand hoki stock, the certification of which had been challenged by some environmental groups.

The authors argue that the
MSC should concentrate on small-scale fisheries. But the largest industrial fisheries should be targeted first - they supply most of the fish for consumption in countries where certification will have an impact. The cost of certification is largely independent of fishery yield, so it is much more cost-effective to certify large fisheries than small ones. We see little evidence that smallscale fisheries are having a lower impact per kilogram of product.

One of the MSC's principles is that "fishing operations should allow for the maintenance of the structure, productivity, function and diversity of the ecosystem". We doubt that any form of conventional agriculture using a plough would meet that standard. Indeed, retailers who reject some MSC-certified fish still sell crops and meat that have high environmental impacts.

Ray Hilborn University of Washington, USA, rayh@uw.edu James H. Cowan Jr Louisiana State University, USA

\section{Investigation of warship sinking}

We wish to clarify any confusion over the sinking of the South Korean navy's ship Cheonan on 26 March this year (for example, see Nature 466, 302-303, 815; 2010).

The report of the multinational Joint Investigation Group has now been released in Korean and English (see www.cheonan46.go.kr/100) and should counter scientific criticisms of the investigation's conclusion that the Cheonan was sunk by a torpedo fired from a North Korean midget submarine.

Choo Kyu ho Embassy of the Republic of Korea (South Korea), London, UK, koreanembinuk@mofat.go.kr 